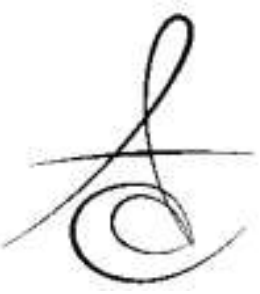

\title{
BİLGİSAYAR DESTEKLİ TASARIM-BİLGİSAYAR DESTEKLİ ÜRETİM SİSTEMLERİNIN FARKLI DENTAL RESTORASYONLARIN KENAR VE İÇ YÜZEY UYUMLARINA ETKİSİNİN DEĞERLENDİRİLMESİ: İN-VİTRO ÇALIŞMA
}

\author{
EVALUATION OF THE EFFECT OF COMPUTER AIDED DESIGN- COMPUTER \\ AIDED MANUFACTURING SYSTEMS ON MARGINAL AND INTERNAL FIT OF \\ DIFFERENT DENTAL RESTORATIONS: AN IN-VITRO STUDY
}

Dr. Öğr. Gör. Merve BENLí*

\author{
Prof. Dr. Bilge GÖKÇEN-ROHLİG*
}

\author{
Makale Kodu/Article code: 3794 \\ Makale Gönderilme tarihi; 16.07 .2018 \\ Kabul Tarihi; 31.07.2019 \\ DOI : $10.17567 /$ ataunidfd.599380
}

Merve Benli: ORCID ID: 0000-0003-2191-113X

Bilge Gökçen-Rohlig: ORCID ID: 0000-0003-3143-9668

\section{öz}

Amaç: Bu çalışmanın amacı, direkt (ağız-içi tarayııı) ve indirekt (ağız-dışı tarayıcı) dijital teknikle üretilen kron ve inley restorasyonlarının kenar ve iç yüzey uyumunu değerlendirmek ve geleneksel teknikle bilgisayar destekli tasarım ve bilgisayar destekli üretim (CAD/CAM) kullanılarak üretilen restorasyonları karşılaştırmaktır.

Materyal ve metod: Kron ve inley restorasyonların üretimi için mandibular sağ ve sol birinci büyük azı fantom dişler kullanılmıştır. Çalışmada 6 grup kron $(n=10), 3$ grup inley $(n=10)$ olmak üzere toplamda 9 grup ve 90 adet örnek bulunmaktadır. Her iki restorasyon tipinin üretiminde direkt dijital, indirekt dijital ve geleneksel yöntem kullanılmıștır. Örneklerin kenar ve iç yüzey uyumunun değerlendirilmesinde replika tekniği kullanılmış olup, ölçümler 50x büyütmeli stereomikroskop altında gerçekleștirilmiştir. İstatistiksel değerlendirme tek yönlü varyans analizi ve tekrarlı ölçümler varyans analizi yöntemleri ile yapılmış olup, gruplar arası karşılaştırmalarda ise Tukey HSD ve Tamhane's T2 testleri kullanılmıştır $(p<0,05)$.

Bulgular: Elde edilen sonuçlara göre, kenar ve iç yüzey uyum değerlerinin ölçü ve üretim tekniğinden etkilendiği görülmüştür. Direkt dijital teknik, indirekt dijital teknik ve geleneksel yönteme göre her iki restorasyon grubunda en iyi sonuçları vermiştir. Tüm gruplarda elde edilen iç yüzey aralık değerlerinin, kenar aralık değerlerinden daha yüksek olduğu saptanmıştır $(p<, 001)$.

Sonuç: Çalışmanın kısıtlılıkları dahilinde, direkt dijital yolla elde edilen kron ve inley restorasyonlarına ait kenar ve iç yüzey uyumları, indirekt dijital ve geleneksel yöntemle üretilen restorasyonlara göre istatistiksel olarak daha iyidir.

Anahtar kelimeler: CAD/CAM, inley, kron, replika teknikleri.

\section{ABSTRACT}

Aim: The aim of this study was to evaluate the marginal and internal fit of crown and inlay restorations that produced with direct (intra-oral scanner) and indirect (extra-oral scanner) digital methods and compare the computer-aided design and computer-aided manufacturing (CAD / CAM) restorations with conventional ones.

Material and Methods: Mandibulary right and left first molar phantom teeth were used to produce the crown and inlay restorations. Totally, there were 9 groups and 90 samples in the study, including 6 groups of crowns $(n=10)$ and 3 groups of inlays $(n=10)$. Direct digital, indirect digital and traditional methods were used in the production of both restoration types. Replica technique was used to evaluate the marginal and internal fit of the samples, and the measurements were performed under a 50x magnification stereomicroscope. One-way analysis of variance and repeated measures of variance analysis were performed for statistical evaluation, and Tukey HSD and Tamhane's T2 tests were used for comparisons between groups ( $p$ $<0.05)$.

Results: According to the obtained results, marginal and internal fit values were influenced by impression and production technique. Direct digital technique gave the best results in both restoration groups compared to indirect digital technique and the conventional method. Internal gap values obtained in all groups were found to be higher than marginal gap values ( $p$ $<.001)$.

Conclusion: Within the limitations of the study, marginal and internal fit values of the crown and inlay restorations obtained with direct digital method were statistically better than the restorations produced by the indirect digital and conventional methods.

Keywords: CAD/CAM, inlay, crown, replica techniques.

\footnotetext{
* İstanbul Üniversitesi, Diș Hekimliği Fakültesi, Protetik Diș Tedavisi A.D. İstanbul
}

Kaynakça Bilgisi: Benli M, Gökçen-Rohlig B. Bilgisayar Destekli Tasarım-Bilgisayar Destekli Üretim Sistemlerinin Farklı Dental Restorasyonların Kenar Ve İç Yüzey Uyumlarına Etkisinin Değerlendirilmesi: İn-Vitro Çalışma. Atatürk Üniv Diş Hek Fak Derg 2020; 30: 1-11

Citation Information: Benli M, Gokcen-Rohlig B. Evaluation Of The Effect Of Computer Alded Design-Computer Alded Manufacturing Systems On Marginal And Internal Fit Of Different Dental Restorations: An In-Vitro Study. J Dent Fac Atatürk Uni 2020; 30: 1-11 


\section{GİRİŞ}

Sabit bölümlü protezlerin başarısında rol oynayan en önemli faktörlerden biri net ve doğru ölçü kaydı alınmasıdır. ${ }^{1}$ Günlük klinik uygulamalarda elastomerik ölçü materyalleri aracılığıyla uygulanan geleneksel ölçü tekniği ve alçı modellerde yapılan üretim metodu mevcut altın standart olarak kabul edilmektedir. ${ }^{2-4}$ Ancak, bu durum geleneksel yöntemin kusursuz olduğu anlamına gelmemekte olup, yöntemin getirdiği bazı dezavantajlar klinik kullanımda birtakım kısıtılıklara neden olmaktadır. Bu kısıtılıklar arasında yer alan ölçü materyalinin genleşme ve büzülmesi ile kullanılan alçı modele bağlı faktörler, teknolojide yaşanan tüm gelişmelere rağmen üstesinden gelinemeyen durumlar olarak varlığını sürdürmektedir. ${ }^{5} \mathrm{Bu}$ bağlamda, geleneksel ölçü yönteminin hataya yatkın yapısını kompanze edebilen ve standardizasyonu arttıran yapısı nedeniyle dijital sistemlerin, daha net ve başarılı dental restorasyonların üretiminde önemli bir alternatif olduğu düşünülmektedir. ${ }^{6}$

Dental teknoloji alanında meydana gelen güncel gelişmeler günlük klinik uygulamalarda dijital sistemlere odaklanmakta, bu sistemler ise sahaya yeniliği dijital veri edinimi ve bilgisayar destekli tasarım ve üretim yoluyla getirmektedir. ${ }^{7-10}$ Yanı sıra, bilgisayar destekli tasarım ve bilgisayar destekli üretim (CAD/ CAM) teknolojisi geleneksel yöntemle teknik hassasiyet ve yüksek maliyet gerektiren dental materyallerin de kullanımını mümkün kılmaktadır. ${ }^{11-13}$

CAD/CAM sisteminin işleyiş mekanizması; geleneksel ölçü, alçı model (indirekt dijital teknik) veya ağız içinden uygun tarayıcılarla doğrudan veri kaydı (direkt dijital teknik) edinimiyle başlar. Geleneksel ölçü kaydına dental alçının dökülmesiyle elde edilen ana modelin taranması yoluyla elde edilen dijital veriler (indirekt dijital teknik- IDT), günlük kullanımda pek çok dental laboratuvarın popüler tekniği haline gelmiştir. Bu bağlamda, direkt dijital teknik (DDT) herhangi bir aracı ölçü ya da model olmaksızın sağladığı doğrudan ağız içi bilgi aktarımı sayesinde, ölçü materyalinin boyutsal değişikliği ya da modele bağlı kısıtılıkları ortadan kaldırmaktadır. Ancak, bu teknikle elde edilen veri kalitesi bitiş çizgisi konumu, periodontal sağlık, sulkusta oluşan kanama, tükürük akış hızı ve hasta uyumu gibi faktörlerden etkilenmektedir. Teknik her ne kadar avantajlı gibi görünse de DDT ile elde edilen ölçü kayıtları; uygulanan teknik, uygulayıcının tecrübesi, oda sıcaklığı ve aydınlatma gibi özelliklere bağlı olarak değişkenlik göstermektedir. ${ }^{14}$ Bu durum güncel
DDT sistemleriyle ilgili sorulara neden olmaktadır. Ancak, bahsedilen güncel sistemlerle ilgili literatürde yeterli çalışma bulunmamaktadır.

Restorasyonun kenar uyumu periodontal sağlığın korunması açısından önem taşırken, iç yüzey uyumu restorasyonun klinik kullanım süresinin uzunluğunda rol oynamaktadır. ${ }^{13,15,16}$ Literatürde, klinik olarak kabul edilebilir kenar aralığı değerinin 10-160 $\mu \mathrm{m}$ olması gerektiği bilgisi mevcutken, iç yüzey aralık değerinin 81-136 $\mu \mathrm{m}$ arasında değişkenlik gösterdiği kabul edilmektedir. ${ }^{17-19}$ Buna bağlı olarak yetersiz kenar uyumu, plak birikimi ve restorasyonu altındaki siman ajanının ağız sıvılarında çözünmesine neden olmakta, bu durum da sekonder çürükler ve periodontal enflamasyona davetiye çıkarmaktadır. ${ }^{20} \mathrm{Bu}$ açıdan, mevcut diş dokusunun korunması açısından klinisyenin dikkate alması gereken bir diğer parametre de iç yüzey uyumdur. ${ }^{21-23}$ Literatür incelendiğinde, kenar ve iç yüzey uyum parametrelerinin genellikle tek yönlü incelendiği ve mevcut çalışmada olduğu gibi her iki parametreyi farklı restorasyon tipleriyle karşılaştırmalı olarak inceleyen araştırmaların eksik olduğu görülmektedir. Çalışma, literatürdeki bu eksikliği gidermeyi hedeflemektedir.

$\mathrm{Bu}$ in vitro çalışmanın amacı, dijital ve geleneksel yolla üretilen kron ve inley restorasyonların kenar ve iç yüzey uyumlarının karşılaştırılmasıdır. Çalışmaya ait sıfır hipotezleri;

1. Restorasyonların kenar ve iç yüzey uyumları açısından gruplar arasında kullanılan ölçü ve üretim yöntemine göre istatistiksel olarak anlamlı bir fark yoktur.

2. Değerlendirilen kenar ve iç yüzey uyumu parametrelerine göre, ölçümlenen diş yüzeyleri arasında grup içi ve gruplar arası istatistiksel olarak anlamlı bir fark yoktur.

\section{MATERYAL VE METOD \\ 1.Çalışma dizaynı}

Çalışma örneklerini hazırlamak amacıyla, sert termoset plastik materyalden üretilen alt ve üst fantom çene modelleri kullanılmıştır (Frasaco ANAVCER; Frasaco GmbH, Tettnang, Almanya). Her bir grup 10 adet örnek içerecek şekilde, kullanılan ölçü ve üretim metoduna göre kron restorasyonlar için 6, inley restorasyonlar için 3 adet grup olmak üzere çalışmada toplam 9 grup bulunmaktadır (güç analizi \%80, alfa seviyesi \%5 olduğunda) (Resim 1,2 ve 3). Çalışma gruplarının özellikleri aşağıda belirtildiği şekilde dizayn edilmiştir: 


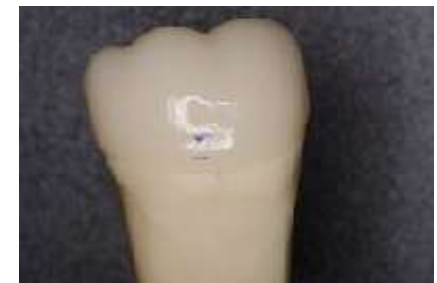

Resim 1. Kron örnek grubunun fantom diş üzerinde frontal düzlemden görünüşü

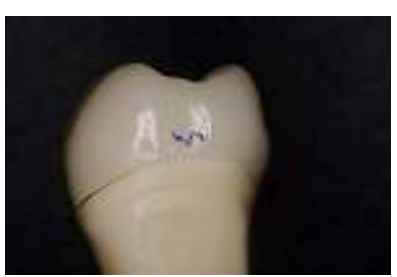

Resim 2. Kron örnek grubunun fantom diş üzerinde sagittal düzlemden görünüşü

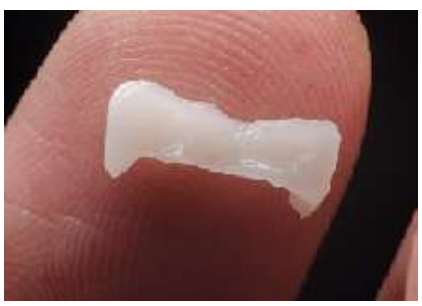

Resim 3. İnley örnek grubunun okluzalden görünüşü

C-IC: İntraoral (ağız-içi) tarayıcı - Lityum disilikat cam seramik, IPS e.max CAD blok (Ivoclar Vivadent AG, Schaan, Liechtenstein)

C-IP: İntraoral (ağız-içi) tarayıcı - Lösitle güçlendirilmiş cam seramik, IPS Empress CAD blok (Ivoclar Vivadent AG, Schaan, Liechtenstein)

C-C: Geleneksel ölçü (Wash tekniği) - Geleneksel vener seramiği, IPS Classic Ceramic (Ivoclar Vivadent AG, Schaan, Liechtenstein)

C-EC: Ekstraoral(ağız-dışı) tarayıcı - Lityum disilikat cam seramik, IPS e.max CAD blok-LT A1/C 14

C-EP: Ekstraoral(ağız-dışı) tarayıcı - Lösitle güçlendirilmiş cam seramik, IPS Empress CAD blok-LT A1/C 14

C-P: Geleneksel ölçü (Wash tekniği) - Lösitle güçlendirilmiş cam seramik, IPS Empress CAD blok-LT A1/C 14

IN-C: Geleneksel ölçü (Wash tekniği) - Lösitle güçlendirilmiş cam seramik, IPS Empress CAD blok- LT A1/C 14
IN-E: Ekstraoral(ağız-dışı) tarayıcı - Lösitle güçlendirilmiş cam seramik, IPS Empress CAD blok-LT A1/C 14

IN-I: İntraoral (ağız-içi) tarayıcı - Lösitle güçlendirilmiş cam seramik, IPS Empress CAD blok- LT A1/C 14

\section{Diş preparasyonu}

Kron gruplarının eldesinde, standardizasyonun sağlanması amacıyla hazır prepare formda üretilen akrilik mandibular sol birinci büyük azı diş kullanıımışıı (Frasaco ANA 4-ZP; Frasaco GmbH, Tettnang, Almanya). Üretici firmanın katalog bilgileri ve araştırmacı tarafından yapılan sayısal ölçümlere göre prepare formda hazır olarak üretilen fantom dişin özellikleri: 2 mm'lik okluzal aşındırma, $1,5 \mathrm{~mm}$ 'lik aksiyal aşındırma, 6 derecelik okluzal yaklaşım açısı, chamfer kenar dizaynı ve $0,5 \mathrm{~mm}$ subgingival kenar seviyesinden oluşmaktadır. Örneklerde herhangi keskin kenar ya da köşe bulunmamaktadır. ${ }^{24}$

İnley gruplarının eldesinde ise, kullanıma uygun ve hazır prepare formda üretilen akrilik dişler mevcut olmadığı için mandibular sağ birinci büyükazı diş mezio-okluzo-distal (MOD) inley restorasyon tasarımı olacak şekilde, tecrübeli bir klinisyen tarafından inley frez seti kullanılarak ve standart inley kavite preparasyon prensipleri izlenerek hazırlanmıştır (ExpertenSet 4561S Keramik-Inlays, Brasseler GmbH, Lemgo, Almanya). ${ }^{23}$ Buna göre hazırlanan inley kavitesi; 8 derecelik konverjans açısı, 2,5 mm derinlikte okluzal kutu ile $3 \mathrm{~mm}$ boğaz genişliğine sahip olup, proksimal gingival marjin seviyesi mine-sement sınırını $1,5 \mathrm{~mm}$ yukarısında olacak şekilde düzenlenmiştir ve keskin kenar ya da köşe bulundurmamaktadır.

\section{3.ölçü protokolü}

Ana model üzerinde hazırlanan geleneksel ölçü kayıtları, polivinil siloksan ölçü materyali, PVS (Imprint 3;3M ESPE GmbH, St Paul, MN, ABD) ve wash tekniği kullanılarak, hazır metal ölçü kaşıklarıyla elde edilmiştir. Elde edilen her ölçü kaydı boşluk, hava kabarcığı gibi hatalar açısından bağımsız bir araştıııı tarafından 2,3 büyütmeli dental büyüteç (2.3XDental Through; TREE, NY, ABD) yardımıyla değerlendirilmiştir. Doğruluğu onaylanan konvansiyonel ölçülere Tip IV sert alçı (Zhermack Elite Rock, Zhermack, Badia Polesine, Rovigo, İtalya) dökülerek çalışma modelleri elde edilmiştir. Ağız-dışı tarayıcının (IDT) kullanıldığı grupların kaydı ise, çalışma modellerinin üretici firmanın önerileri doğrultusunda taranmasıyla elde edilmiştir (InEosX5; Sirona Dental Systems, Bensheim, Almanya). Bu amaçla, sistemin net tarama yapabilmesi 
için alçı modellere, ince tabaka halinde titanyum dioksit opak pudra (Vita CEREC Powder, Patterson Dental Company, St Paul, MN, ABD) uygulaması yapılmıştır.

DDT gruplarının veri kayıtları optik triangulasyon ve konfokal mikroskopi teknolojisine dayanarak üretilen ağız-içi tarayıcı (CEREC AC Omnicam, Sirona Dental Systems, Bensheim, Almanya) yardımıyla ana modelin doğrudan taratılması şeklinde elde edilmiştir. Tarama sırasında ana model yere paralel konumlandırılmış ve model üzerindeki her diş önceden belirlenen tarama sırasına göre kaydedilmiştir. Tarama işleminin ardından elde edilen stereolitografi dosyaları (STL) optimizasyon için üretici firmaya gönderilerek değerlendirilmiş ve üretim prosedürü için onay alınmıştır.

\section{Restorasyon üretimi}

Geleneksel yöntem gruplarına ait örneklerin üretiminde, üretici firmanın önerileri ve standart kron restorasyon üretim protokolü esas alınmıştır. ${ }^{25}$

IDT ve DDT yöntemlerine ait örneklerin taranması yoluyla elde edilen dijital veriler, sistemin yazılım programına aktarılarak (CEREC Connect Software 4.3; Sirona) biyojenerik restorasyon tasarımı gerçekleştirilmiştir. Restorasyon dizaynı sırasında belirlenen referans değerler: marjin seviyesinin $0,8 \mathrm{~mm}$ okluzalinden başlamak üzere $30 \mu \mathrm{m}$ siman aralığı, 0,8 mm freze yarıçap ayarı ve 0,6 mm'lik koping kalınlığı şeklindedir ve üretim prosedürü sistemin bağlı olduğu aşındırma ünitesine aktarım sağlanarak gerçekleştirilmiştir. Çalışma gruplarından; C-IP, C-EP, C-P, IN-C, IN-I ve IN-E gruplarına ait örneklerin üretiminde IPS Empress CAD bloklar kullanılmış olup, C-IC ve C-EC gruplarının eldesinde ise IPS e.max CAD bloklardan faydalanılmıştır (Resim 4-12).

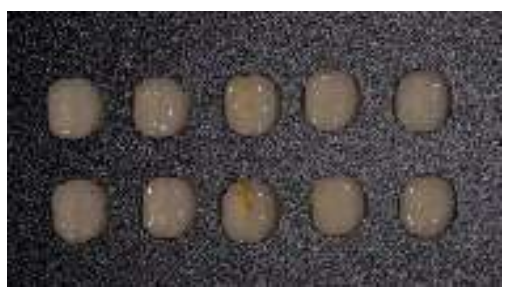

Resim 4. C-IC örnek grubunun okluzalden görünüşü

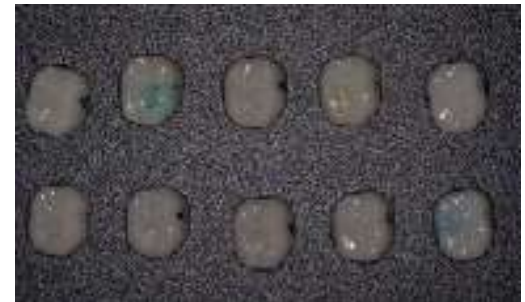

Resim 5. C-C örnek grubunun okluzalden görünüşü

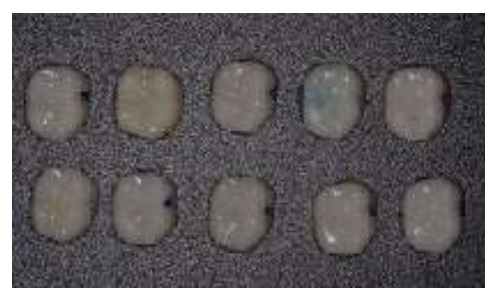

Resim 6. C-IP örnek grubunun okluzalden görünüşü

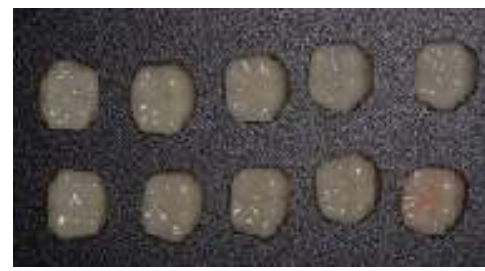

Resim 7. C-EC örnek grubunun okluzalden görünüşü

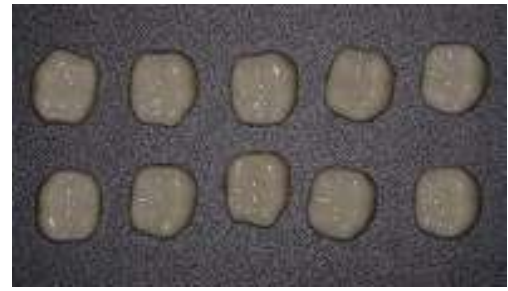

Resim 8. C-EP örnek grubunun okluzalden görünüşü

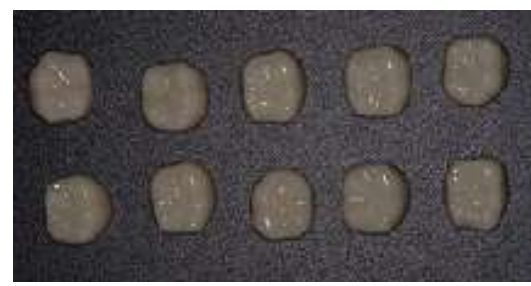

Resim 9. C-P örnek grubunun okluzalden görünüşü 


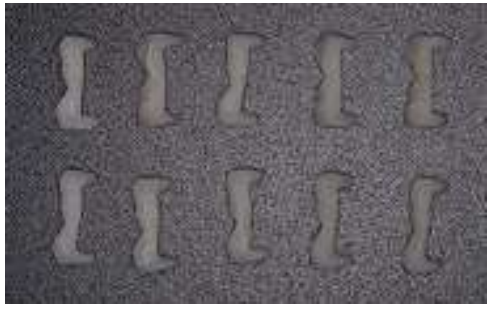

Resim 10. IN-C örnek grubunun okluzalden görünüşü

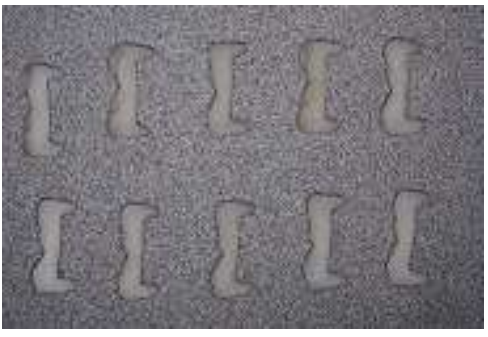

Resim 11. IN-E örnek grubunun okluzalden görünüşü

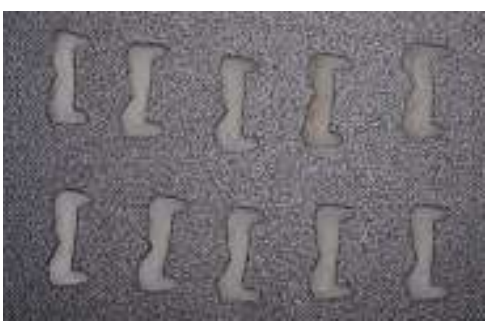

Resim 12. IN-I örnek grubunun okluzalden görünüşü

\section{Silikon replikaların eldesi}

Restorasyonların kenar ve iç yüzey uyumlarını değerlendirmek amacıyla toplam örneklerden silikon replikalar elde edilmiştir. Restorasyonun iç yüzeyiyle dayanak diş arasında oluşan açıklığı kaydetmek için literatürde sıklıkla tercih edilen 'replika tekniği' mevcut çalışmada kullanılmıştır. ${ }^{14}$ Tekniğin uygulanması sırasında iki farklı renkteki akıcı kıvamlı polivinil siloksan ölçü malzemesi (Express 2 Ultra-Light Body Quick, 3M ESPE, St Paul, MN, ABD; Bonasil A+ Light HTS Bonasil A, DMP, ABD), diş-restorasyon arasındaki aralığı taklit etmek amacıyla restorasyonun iç yüzeyine sırayla uygulanmıştır. Materyallerin polimerizasyonu sonucunda elde edilen replikalar, bisturi ile önce bukko-lingual ardından mezyo-distal yönde kesilerek 4 eşit parçaya bölünmüşlerdir ( Resim 13-14).

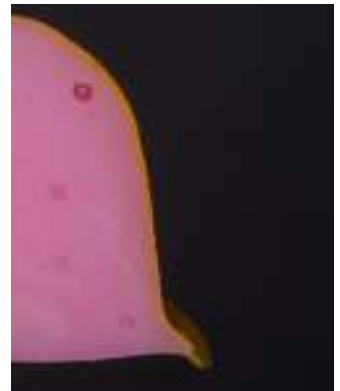

Resim 13. Kron örneklerinin kenar ve iç yüzey uyumunu gösteren silikon replika kesiti.

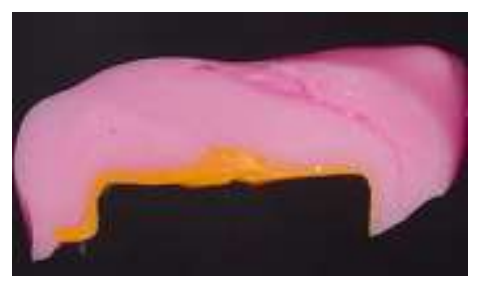

Resim 14. İnley örneklerinin kenar ve iç yüzey uyumunu gösteren silikon replika kesiti.

\section{6. Ölçümler}

Restorasyonların kenar ve iç yüzey uyumlarının değerlendirmesi 50X'lik büyütme altındaki stereomikroskop ile yapılmıştır (M-80, Leica, Wetzlar, Almanya). Ölçüm sırasında elde edilen görüntüler dijital kamera (Hitachi CCTV HV-720E, Hitachi, Tokyo, Japonya) aracılığıyla bilgisayara aktarılarak bir görüntü-analiz yazılımı aracılığıyla ölçüm işlemi gerçekleştirilmiştir.

Çalışmada uyum değerlendirmesi amacıyla kulIanılan referans noktalar Holmes ve arkadaşlarının çalışmasında belirtildiği üzere sırasıyla şunlardan oluşmaktadır: a) kenar aralığı, b) aksiyal duvar, c) aksiyookluzal açı, d) okluzal yüzey. ${ }^{22}$ Buna göre, kenar aralığı parametresi restorasyon bitim sınırı ile dişin basamağı arasındaki mesafe olarak belirlenirken, iç yüzey aralığı ise restorasyonun iç yüzeyi ile prepare dişin aksiyal bölge, okluzal krest ve okluzal fossa arasındaki mesafe olarak kabul edilmektedir. Çalışmada her örnek için belirlenen yüzey ve noktalardan 3 defa ölçüm yapılarak ortalama veriler değerlendirmede kullanılmıştır. Örnek başı 36 noktadan ölçüm yapılmış olup, toplamda 3240 ölçüm noktası kaydedilmiştir. Tüm veriler mikron $(\mu \mathrm{m})$ düzeyinde sisteme (Microsoft Excel 2007, Microsoft Corporation, Redmond, Washington, ABD) aktarılarak gerekli hesaplamalar gerçekleştirilmiştir.

\section{7.İstatistiksel değerlendirme}

Örneklere ait ölçümlerin istatistiksel değerlendirmesi SPSS V23(IBM SPSS V23, IBM Corporation, 
Chicago, Illinois, ABD) paket programı aracılığıyla analiz edilmiştir. Verilerin normal dağılıma uygunluğu Shapiro Wilk testi ile incelenmiştir. Veriler normal dağıIıma uygun olduğu için karşılaştırmalarda tek yönlü varyans analizi ile tekrarlı ölçümler varyans analizi yöntemleri kullanılmıştır. Gruplar arasındaki farkılığın hangi gruptan kaynaklandığını tespit etmede ise, varyansların homojenliği Levene testi ile incelendikten sonra Tukey HSD ve Tamhane's T2 testleri uygulanmıştır. Sonuçlar aritmetik ortalama \pm standart sapma olarak sunulmuş olup, anlamlılık düzeyi $p<0,05$ olarak alınmıştır.

\section{BULGULAR}

Çalışma gruplarına ait ortalama kenar ve iç yüzey aralık değerlerinin ortalama ve standart sapmaları Tablo 1'de verilmiştir. Elde edilen sonuçlara göre, ölçü ve üretim metodunun değerlendirilen uyum parametrelerini istatistiksel olarak anlamlı düzeyde etkilediği görülmüştür $(p=.000)$. Kenar aralık değerleri açısından en düşük değerleri veren kron grubu C-IP iken, en yüksek değerleri C-C grubu vermiştir. İnley restorasyonlarda ise, en düşük kenar aralık değerleri IN-I grubunda saptanmış olup, en yüksek değerler INC grubunda görülmüştür. Ağız-içi tarayıcının kullanıldığı DDT diğer iki yönteme göre istatistiksel olarak daha üstün sonuçlar göstermiş olup, değerlendirilen kenar ve iç yüzey uyum parametreleri açısından en düşük uyumu geleneksel yöntem göstermiştir. İç yüzey aralık değerleri analiz edildiğinde ise, gruplar arasında istatistiksel olarak anlamlı düzeyde farklılık oluştuğu saptanmıştır $(p<, 001)$.

Örneklere ait grup-içi değerlendirmeler Tablo 2'de gösterilmektedir. Buna göre, kron grupları içerisinde en yüksek aralık değerleri C-C grubunun

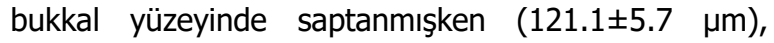
mezial ve lingual yüzeylerin distal ve bukkal yüzeylere göre istatistiksel olarak daha iyi sonuçlar verdiği görülmüştür. Okluzal aralık değerlerine bakıldığında ise, en iyi sonuçlar IN-I grubunda elde edilmiş olup, en yüksek değerlerin C-C grubunda olduğu belirlenmiştir (Tablo 3).

Tablo 1. İncelenen diş yüzeyine göre restorasyonların kenar ve iç yüzey uyumlarının gruplar arası karşılaştırması.

\begin{tabular}{|l|c|c|c|c|c|}
\hline Kenar Uyumu (Gruplar) & Bukkal yüzey & Lingual yüzey & Mezialyüzey & Distal yüzey & \\
& & & & & \\
\hline C-IC & $77,3 \pm 3,7 \mathrm{a}$ & $73,7 \pm 2,4 \mathrm{a}$ & $72,6 \pm 4,0 \mathrm{ab}$ & $73,5 \pm 2,7 \mathrm{a}$ & \\
\hline C-IP & $75,5 \pm 2,3 \mathrm{a}$ & $73,3 \pm 4 \mathrm{a}$ & $77,6 \pm 2,8 \mathrm{~b}$ & $74,5 \pm 2,6 \mathrm{a}$ & \\
\hline C-C & $121,1 \pm 5,7 \mathrm{~d}$ & $108,8 \pm 4,2 \mathrm{c}$ & $115,8 \pm 6,9 \mathrm{~d}$ & $118,8 \pm 7,5 \mathrm{~d}$ & \\
\hline C-EC & $100,7 \pm 4,7 \mathrm{~b}$ & $97 \pm 4 \mathrm{~b}$ & $99,3 \pm 2,2 \mathrm{c}$ & $100,0 \pm 3,2 \mathrm{bc}$ & \\
\hline C-EP & $101 \pm 3,9 \mathrm{~b}$ & $98,5 \pm 4,1 \mathrm{~b}$ & $100,0 \pm 2,7 \mathrm{c}$ & $97,9 \pm 2,9 \mathrm{~b}$ & \\
\hline C-P & $113,6 \pm 5,5 \mathrm{c}$ & $108,7 \pm 5 \mathrm{c}$ & $101,4 \pm 3,7 \mathrm{c}$ & $104,1 \pm 6,5 \mathrm{~b}$ & \\
\hline IN-C & $118,8 \pm 6,7 \mathrm{~cd}$ & $112 \pm 6,5 \mathrm{c}$ & $126,6 \pm 5,3 \mathrm{e}$ & $120,5 \pm 5,5 \mathrm{~d}$ & \\
\hline IN-E & $98,1 \pm 2,6 \mathrm{~b}$ & $96,2 \pm 2,5 \mathrm{~b}$ & $99,1 \pm 3,0 \mathrm{c}$ & $98,9 \pm 2,7 \mathrm{bc}$ & \\
\hline IN-I & $77,8 \pm 2,2 \mathrm{a}$ & $74 \pm 3,5 \mathrm{a}$ & $68,0 \pm 3,3 \mathrm{a}$ & $70,3 \pm 3,0 \mathrm{a}$ & \\
\hline Test istatistiği & 197,8 & 172,0 & 286,7 & 216,8 & \\
\hline & & & & & \\
\hline İç Yüzey Uyumu(Gruplar) & Bukkal yüzey & Lingual yüzey & Mezial yüzey & Distal yüzey & Okluzal yüzey \\
\hline C-IC & $109,3 \pm 4,6 \mathrm{a}$ & $98,4 \pm 2,1 \mathrm{a}$ & $93,8 \pm 3,0 \mathrm{a}$ & $88,5 \pm 3,5 \mathrm{a}$ & $213,3 \pm 4,1 \mathrm{de}$ \\
\hline C-IP & $115,2 \pm 6,6 \mathrm{a}$ & $103,4 \pm 5,4 \mathrm{a}$ & $114,8 \pm 5,5 \mathrm{~b}$ & $114,9 \pm 5,5 \mathrm{~b}$ & $222,2 \pm 6,3 \mathrm{e}$ \\
\hline C-C & $235,9 \pm 28 \mathrm{e}$ & $231 \pm 13,1 \mathrm{e}$ & $235,8 \pm 13,8 \mathrm{e}$ & $231,2 \pm 12,4 \mathrm{~g}$ & $277,4 \pm 24,3 \mathrm{~g}$ \\
\hline C-EC & $149,5 \pm 15,1 \mathrm{~b}$ & $138 \pm 10,8 \mathrm{~b}$ & $138,4 \pm 9,6 \mathrm{c}$ & $137,0 \pm 8,4 \mathrm{c}$ & $211,6 \pm 14,6 \mathrm{de}$ \\
\hline C-EP & $145,9 \pm 6,5 \mathrm{~b}$ & $139,7 \pm 9,1 \mathrm{~b}$ & $137,4 \pm 8,4 \mathrm{c}$ & $149,8 \pm 7,7 \mathrm{~d}$ & $203,1 \pm 6,6 \mathrm{~d}$ \\
\hline C-P & $182 \pm 6,5 \mathrm{c}$ & $174,3 \pm 5,8 \mathrm{c}$ & $167,0 \pm 13,4 \mathrm{~d}$ & $180,3 \pm 3,5 \mathrm{f}$ & $241,2 \pm 11,2 \mathrm{f}$ \\
\hline IN-C & $209,4 \pm 13,5 \mathrm{~d}$ & $197,7 \pm 10,2 \mathrm{~d}$ & $236,7 \pm 10,9 \mathrm{e}$ & $231,0 \pm 13,9 \mathrm{~g}$ & $122,3 \pm 6,0 \mathrm{c}$ \\
\hline IN-E & $171,6 \pm 5,8 \mathrm{c}$ & $169,7 \pm 6,3 \mathrm{c}$ & $164,4 \pm 4,9 \mathrm{~d}$ & $168,9 \pm 6,2 \mathrm{e}$ & $84,5 \pm 4,4 \mathrm{~b}$ \\
\hline IN-I & $115,8 \pm 4,6 \mathrm{a}$ & $105,3 \pm 5,7 \mathrm{a}$ & $87,4 \pm 4,4 \mathrm{a}$ & $82,3 \pm 6,1 \mathrm{a}$ & $67,2 \pm 3,1 \mathrm{a}$ \\
\hline Test istatistiği & $\mathrm{F}=151,1$ & $\mathrm{~F}=371,6$ & $\mathrm{~F}=441,1$ & $\mathrm{~F}=533,4$ & F=526,6 \\
\hline P & $<0,001$ & $<0,001$ & $<0,001$ & $<0,001$ & \\
\hline
\end{tabular}

a-g: Değerlendirilen her yüzey için aynı harfi taşıyan gruplar arasında istatistiksel olarak anlamlı bir fark yoktur. F: Tek yönlü varyans analizi test istatistiği p<0,05: İstatistiksel anlamlılık düzeyi 
Tablo 2. İncelenen diş yüzeyine göre restorasyonların kenar ve iç yüzey uyumlarının grup içi karşılaştırması.

\begin{tabular}{|c|c|c|c|c|c|c|}
\hline Kenar Uyumu (Gruplar) & Bukkal yüzey & Lingual yüzey & Mezialyüzey & Distal yüzey & Test istatistiği & $p$ \\
\hline C-IC & $77,3 \pm 3,7 a$ & $73,7 \pm 2,4 a b$ & $72,6 \pm 4,0 b$ & $73,5 \pm 2,7 b$ & $\mathrm{~F}=7,8$ & 0,007 \\
\hline C-IP & $75,5 \pm 2,3 a$ & $73,3 \pm 4 a$ & $77,6 \pm 2,8 b$ & $74,5 \pm 2,6 a$ & $\mathrm{~F}=12,0$ & 0,002 \\
\hline $\mathrm{C}-\mathrm{C}$ & $121,1 \pm 5,7 b$ & $108,8 \pm 4,2 a$ & $115,8 \pm 6,9 a b$ & $118,8 \pm 7,5 b$ & $F=19,2$ & $<0,001$ \\
\hline C-EC & $100,7 \pm 4,7 a$ & $97 \pm 4 b$ & $99,3 \pm 2,2 a b$ & $100,0 \pm 3,2 a b$ & $F=9,6$ & 0,004 \\
\hline C-EP & $101 \pm 3,9$ & $98,5 \pm 4,1$ & $100,0 \pm 2,7$ & $97,9 \pm 2,9$ & $\mathrm{~F}=1,4$ & 0,313 \\
\hline $\mathrm{C}-\mathrm{P}$ & $113,6 \pm 5,5 a$ & $108,7 \pm 5 b$ & $101,4 \pm 3,7 c$ & $104,1 \pm 6,5 c$ & $\mathrm{~F}=22,1$ & $<0,001$ \\
\hline IN-C & $118,8 \pm 6,7 b$ & $112 \pm 6,5 a$ & $126,6 \pm 5,3 c$ & $120,5 \pm 5,5 b c$ & $\mathrm{~F}=28,1$ & $<0,001$ \\
\hline IN-E & $98,1 \pm 2,6$ & $96,2 \pm 2,5$ & $99,1 \pm 3,0$ & $98,9 \pm 2,7$ & $F=4,4$ & 0,050 \\
\hline IN-I & $77,8 \pm 2,2 a$ & $74 \pm 3,5 a$ & $68,0 \pm 3,3 b$ & $70,3 \pm 3,0 b$ & $F=36,5$ & $<0,001$ \\
\hline İç Yüzey Uyumu (Gruplar) & Bukkal yüzey & Lingual yüzey & Mezialyüzey & Distal yüzey & Test istatistiği & $\boldsymbol{p}$ \\
\hline C-IC & $109,3 \pm 4,6 a$ & $98,4 \pm 2,1 b$ & $93,8 \pm 3,0 \mathrm{c}$ & $88,5 \pm 3,5 d$ & $F=39,9$ & $<0,001$ \\
\hline C-IP & $115,2 \pm 6,6 a$ & $103,4 \pm 5,4 b$ & $114,8 \pm 5,5 a$ & $114,9 \pm 5,5 a$ & $\mathrm{~F}=18,3$ & $<0,001$ \\
\hline $\mathrm{C}-\mathrm{C}$ & $235,9 \pm 28$ & $231 \pm 13,1$ & $235,8 \pm 13,8$ & $231,2 \pm 12,4$ & $F=0,4$ & 0,738 \\
\hline C-EC & $149,5 \pm 15,1 a$ & $138 \pm 10,8 a b$ & $138,4 \pm 9,6 a b$ & $137,0 \pm 8,4 b$ & $\mathrm{~F}=4,9$ & 0,027 \\
\hline C-EP & $145,9 \pm 6,5$ & $139,7 \pm 9,1$ & $137,4 \pm 8,4$ & $149,8 \pm 7,7$ & $\mathrm{~F}=3,9$ & 0,090 \\
\hline C-P & $182 \pm 6,5 a$ & $174,3 \pm 5.8 \mathrm{~b}$ & $167,0 \pm 13,4 b$ & $180,3 \pm 3,5 a b$ & $\mathrm{~F}=18,0$ & $<0,001$ \\
\hline IN-C & $209,4 \pm 13,5 c$ & $197,7 \pm 10,2 a$ & $236,7 \pm 10,9 b$ & $231,0 \pm 13,9 b c$ & $\mathrm{~F}=17,2$ & $<0,001$ \\
\hline IN-E & $171,6 \pm 5,8$ & $169,7 \pm 6,3$ & $164,4 \pm 4,9$ & $168,9 \pm 6,2$ & $F=2,5$ & 0,123 \\
\hline IN-I & $115,8 \pm 4,6 a$ & $105,3 \pm 5,7 b$ & $87,4 \pm 4,4 c$ & $82,3 \pm 6,1 c$ & $F=157,8$ & $<0,001$ \\
\hline
\end{tabular}

a-d: Grup içinde aynı harfi taşıyan yüzeyler arasında istatistiksel olarak anlamlı bir fark yoktur.

F: Tekrarlı ölçümler varyans analizi test istatistiği

$p<0,05$ : İstatistiksel anlamlılık düzeyi

Tablo 3. Restorasyonların okluzal aralık değerlerinin gruplar arası karşılaştırması.

\begin{tabular}{|l|l|c|c|}
\hline $\begin{array}{c}\text { Restorasyon } \\
\text { grubu }\end{array}$ & Okluzal yüzey & $\begin{array}{c}\text { Test } \\
\text { istatistiği }\end{array}$ & $\boldsymbol{p}$ \\
\hline C-IC & $213,3 \pm 4,1 \mathrm{de}$ & \multirow{2}{*}{ F=526,6 } & $<0,001$ \\
\hline C-IP & $222,2 \pm 6,3 \mathrm{e}$ & & \\
\hline C-C & $277,4 \pm 24,3 \mathrm{~g}$ & & \\
\hline C-EC & $211,6 \pm 14,6 \mathrm{de}$ & & \\
\cline { 1 - 2 } C-EP & $203,1 \pm 6,6 \mathrm{~d}$ & & \\
\hline C-P & $241,2 \pm 11,2 \mathrm{f}$ & & \\
\hline IN-C & $122,3 \pm 6,0 \mathrm{c}$ & & \\
\hline IN-E & $84,5 \pm 4,4 \mathrm{~b}$ & & \\
\hline IN-I & $67,2 \pm 3,1 \mathrm{a}$ & & \\
\hline
\end{tabular}

a-g: Aynı harfi taşıyan gruplar arasında istatistiksel olarak anlamlı bir fark yoktur.

F: Tek yönlü varyans analizi test istatistiği

$p<0,05$ : İstatistiksel anlamlılık düzeyi

\section{TARTIŞMA}

$\mathrm{Bu}$ in-vitro çalışmada, protetik restorasyonların elde edilmesinde kullanılan üç farklı ölçü ve üretim metodunun netlik ve doğruluk değerlendirmesi yapılmıştır. Değerlendirilen kenar ve iç yüzey uyum parametrelerine göre, ağız-içi tarayıcının kullanıldığı gruplar (DDT), ağız-dışı tarayıcı ve geleneksel metod gruplarına göre istatistiksel olarak anlamlı derecede daha iyi sonuçlar vermiştir. Her iki restorasyon grubunda elde edilen sonuçlar, DDT sisteminin daha uyumlu restorasyonların üretimini sağladığı yönündedir. Bu nedenle çalışmanın başında belirtilen iki sıfır hipotezi de reddedilmiştir.

Güncel literatür incelendiğinde, CAD/CAM sistemleriyle elde edilen restorasyonların kenar ve iç yüzey uyumlarıyla ilgili değişken sonuçların olduğu görülmektedir. Mevcut çalışmalar incelendiğinde, bir grup araştırmacı konvansiyonel yöntemin restorasyon üretiminde daha avantajlı olduğunu savunurken, bir grup araştırmacı ise dijital sistemlerin daha üstün sonuçlar verdiğini bildirmektedir. ${ }^{14,21,27-29} \mathrm{Bu}$ durum, üretim sırasında kullanılan dijital sistemin türüne göre değişkenlik gösterir nitelikte olup, konuyla ilgili hem kenar hem de iç yüzey uyum parametrelerinin birlikte değerlendirildiği yeterli sayıda çalışma olmadığı görülmektedir. Mevcut çalışma, literatürdeki bu eksikliği gidermek amacıyla güncel DDT sistemini (CEREC AC Omnicam) kullanarak farklı restorasyon tiplerindeki uyum parametrelerini araştırmıştır. Çalışmamızda olduğu gibi farklı restorasyon türlerini birlikte değerlendiren çalışma sayısı literatürde az olmakla beraber elde edilen sonuçlar karşılaştırıldığında, mevcut çalışmamızdaki kenar uyumu değerlerinin Wolfart ve arkadaşlarının yaptığı çalışmadan daha düşük olduğu saptanmıştır. ${ }^{30}$ Konuyla ilgili benzer niteliğe sahip diğer bir çalışmada ise, elde edilen kenar aralığı değerlerinin mevcut çalışmadan daha düşük olduğu saptanırken, iç yüzey aralığı değerlerinin daha yüksek olduğu görül- 
müştür. ${ }^{31}$ Çalışmalar arası farklı niceliklerde elde edilen bu sonuçların çalışma dizaynı, üretim metodu ve örnekleme bağlı olduğu düşünülmekte, doğru karşılaştırmanın yapılabilmesi adına standart prensiplere sahip çalışmaların gerçekleştirilmesi gerekliliği ortaya çıkmaktadır.

Teknolojide meydana gelen güncel gelişmeler diş hekimliği alanında da etkisini göstermekte olup, CAD / CAM teknolojisinin günlük pratikte daha popüler hale gelmesini sağlamaktadır. Bu amaçla, CEREC Sistemi'nin piyasaya sürdüğü en son ürünlerden biri AC Omnicam'dir.Sistemin ardışık verileri bir araya getirerek üç boyutlu model oluşturma özelliği, veri kaydı açısından avantajıdır ve bu özellik bir önceki sürüm olan Bluecam'de mevcut değildir. ${ }^{32}$ Yanı sıra sistemin doğal renkte veri aktarımı sağlaması ve tarama için pudra kullanımı gerektirmemesi daha geniş alanların taranmasında avantaj sağlamakta olup, mevcut çalışmada elde edilen sonuçların bu durumdan etkilendiği düşünülmektedir ki istatistiksel olarak en iyi kenar ve iç yüzey uyumu değerleri DDT gruplarında ölçümlenmiştir. Çalışmada incelen parametreler açısından, en yüksek aralık değerlerinin geleneksel metodun kullanıldığı gruplarda olduğu saptanmıştır. Bu durumun, metodun iş akışı, üretim metodunun gerçekleştirilmesindeki insan faktörü, teknisyene bağlı değişkenler, tekniğin içeriğinde faydalanılan materyaller ve materyallerin fiziksel ve mekanik özelliklerine bağlı olduğu düşünülmektedir. Geleneksel metot uygulamasında yer alan alçı ve ölçü materyalleri gibi ara aşamaların DDT gibi doğrudan veri eldesi sağlayan dijital sistemlerde olmayışı, ikincil modellerin eldesinde karşılaşılan hata oranını azaltmaktadır. Bu yolla, ara aşama sayısının düşürülmesi, materyale bağlı kısıtıılıkların azaltılması ve olası risk yüzdesinin düşürülmesi sağlanarak restorasyonların uyum dereceleri artmakta olup, mevcut çalışmanın literatürdeki verilerle uyumlu sonuçlara sahip olduğu görülmektedir. ${ }^{32}$ Diğer yandan, titanyum dioksit pudra uygulaması, elde edilen alçı model üzerinden tarama yapılması ya da model üzerindeki pudra kalınlığı gibi kısmi limitasyonların bulunduğu ağız-dışı yöntemde de değerlendirilen uyum parametrelerinin etkilendiği görülmektedir. Bu durum, çalışmada ağız-içi tarayıcının kullanıldığı yöntemin diğer gruplara göre neden daha uyumlu sonuçlar verdiğini açıklar niteliktedir.

Literatürde CAD/CAM sistemleri aracılığıyla üretilen restorasyonların kenar ve iç yüzey uyumlarının değerlendirildiği diğer çalışmalar incelendiğinde, mevcut çalışmada elde edilen sonuçların rapor edilen sonuçlardan istatistiksel olarak bir miktar daha yüksek olduğu görülmektedir. Araştırıcılar buna sebep olarak restorasyonların üst yapı seramiği uygulamasından sonra incelenmesini göstermekte olup, literatürde daha düşük sonuçları içeren çalışmaların sadece alt yapı materyalinin değerlendirilmesinden kaynaklandığını düşünmektedirler. ${ }^{32,33}$ Yanı sıra, in-vitro dizayn sebebiyle elde edilen sonuçların, çalışmanın in-vivo olacak şekilde dizayn edilmesi halinde daha yüksek değerleri ortaya çıkaracağı düşünülmektedir. Bu konuyla ilgili benzer dizayna sahip çalışmalar incelendiğinde, elde edilen uyum parametrelerinin mevcut çalışmadan istatistiksel olarak bir miktar daha yüksek olduğu görülmekte, buna sebep olarak da in-vivo tasarımın getirdiği ağız içi ortam şartları, prepare edilen dişin durumu, uygulanan parmak basıncı, ölçümlenen nokta sayısı, silikon replika elde etmekteki kısıtılıklar, hastaya bağlı faktörler ve klinik şartların olduğu düşünülmektedir. ${ }^{30,34}$ Çalışmanın sonuçlarını etkileyen diğer faktör ise, kullanılan dijital sistemin tipi ve çalışma prensibidir. Mevcut çalışmada kullanılan DDT sistemi güncel AC Omnicam sistemi olup, sistem üçışık demetinin tek noktaya odaklanmasını içeren ışık triangulasyonu prensibine dayanmaktadır. Bu durumun, tarama kalitesini arttırarak daha doğru veri kaydı edinmeyi sağladığı düşünülmektedir. Ölçümlerde etkisi olan diğer faktörler; örneklem büyüklüğü, incelenen diş tipi ve ölçüm yapılan noktaların çeşitliliğidir. Çalışmada, literatürdeki diğer çalışmalarla doğru karşılaştırmayı yapabilmek ve standardize sonuçlar elde etmek adına büyük azı dişleri tercih edilmiştir. Bununla ilgili olarak Reich ve arkadaşlarının yaptığı çalışma uyarınca, büyük azı dişlerinin küçük azılara oranla daha geniş yüzey alanına sahip olmaları, bu sebeple de elde edilen sonuçların daha yüksek olduğu yönündedir. ${ }^{35}$

Mevcut çalışmanın sonuçları, literatürde yer alan farklı materyal ve üretim metodlarına sahip olan diğer çalışmalarla karşılaştırıldığında, restorasyonun üretildiği materyal ve kullanılan cihazın farklııı oluşturduğu görülmektedir. Mevcut çalışmayla benzer parametrelerin araştırıldığı bir çalışmada, lityum disilikat ve zirkonyum-oksit içerikli seramik türleri ile üretimde Lava Scan (Lava Scan; 3MESPE) sistemi kullanılmış olup, mevcut çalışmaya göre daha yüksek kenar ve iç yüzey aralık değerlerinin elde edildiği görülmektedir. ${ }^{34}$ Park ve arkadaşları tarafından yapılan bir diğer çalışmada ise, CEREC Bluecam sistemi ile nano-kompozit CAD/CAM materyali kullanılarak üretilen restorasyonlarda elde edilen kenar aralık değerlerinin mevcut çalışmadan daha düşük olması, kullanılan materyal tipi 
ve üretim sisteminin uyum parametrelerini etkileyeceği bilgisini desteklemektedir. ${ }^{31}$ Buna göre, nano-kompozit türevi CAD/CAM materyallerinden üretilen restorasyonlarda uyum parametresinin daha yüksek oranda elde edileceği düşünülmektedir. Ancak, net sonuçlara ulaşılabilmesi için konuyla ilgili daha fazla çalışmaya ihtiyaç duyulmaktadır.

Sabit protetik restorasyonların kenar ve iç yüzey uyumlarını değerlendiren sistematik bir incelemede, aynı sistemlerin kullanıldığı araştırmalarda varyasyonel sonuçların ortaya çıktığı görülmüş, buna açıklama olarak da çalışmalarda izlenen farklı metodolojik yolaklar gösterilmiştir. ${ }^{36} \mathrm{Bu}$ nedenle, çalışmalar arasındaki karşılaştırmaların seçici olarak yerine getirilmesi gerekmektedir. Çalışmada bu gerekliliği sağlayabilmek adına literatürde diş-restorasyon arasındaki uyum parametrelerini değerlendirmek amacıyla güvenli, girişimsel olmayan ve pratik bir teknik olduğu için sıklıkla tercih edilen 'replika tekniği'nden faydalanılmıştır. ${ }^{26,37,38} \mathrm{Bu}$ teknik, Holmes ve arkadaşlarının çalışmasında, restorasyonların uyumsuzluğunu tanımlayan ve hem kenar hem de iç yüzey aralıklarının değerlendirilmesini sağlayan, net bir teknik olarak doğrulanmıştır. ${ }^{26}$ Yanı sıra, bu teknik kullanılarak elde edilen düşük viskoziteli PVS materyal kalınlığının, simantasyon prosedürü sonucu oluşan kenar aralık değerinden istatistiksel olarak farklılık göstermediği saptanmıştır. ${ }^{39}$ Bahsedilen bu ve bu gibi destekleyici etmenler ışığında, çalışmada doğru veri eldesi adına bu teknik kullanılmıştır.

Literatürde, mevcut çalışmamızda olduğu üzere farklı iki tipte restorasyonun (kron ve inley) incelendiği araştırma sayısı kısıtlı olup, elde edilen sonuçların var olan verilerle uyumlu olduğu görülmektedir. ${ }^{31}$ Elde edilen sonuçlara göre, kenar ve iç yüzey uyum parametrelerinde her iki restorasyon türünün istatistiksel olarak yakın değerler verdiği, ancak okluzal yüzey aralığının kron restorasyonlarda daha fazla olduğu saptanmıştır. Bu duruma sebep olarak, dayanak dişin dizaynı ve uygulanan preparasyon tekniği düşünülmektedir. ${ }^{31,40}$ Çalışmamıza benzer dizaynda gerçekleştirilen Park ve arkadaşlarının yaptığı çalışmada, bahsedilen olası etmenlere ek olarak kullanılan yazılım programı ve milleme ünitesinin de farklı sonuçları doğurabileceği geçmektedir. ${ }^{31}$ Yüzey aralık değerlerinin fazla olduğu alanlar, restorasyonun diş ile olan uyumunu azaltıp, restoratif materyalin incelmesine neden olacağından, restorasyonun klinik kullanım süresi ve dayanıklıı̆ını olumsuz yönde etkileme potansiyeli gösterecektir. Bu durum, klinik uygulamalarda restorasyonun dizaynından itibaren teslimine kadar olan süreçte ek önlemler gerektirmesi itibariyle önem taşımaktadır.

Çalışmada elde edilen sonuçlara göre, DDT sistemi diğer yöntemlerle karşılaştırıldığında istatistiksel olarak anlamlı düzeyde daha iyi sonuçlar vermiştir. Bu durum, Jeong ve arkadaşlarının yaptığı çalışmanın sonuçlarıyla uyumlu olmamakla birlikte, ağız-içi tarayıcıların kullanıldığı tekniğin protetik restorasyonların eldesi ve veri aktarımında laboratuvar tarayıcılarına önemli bir alternatif olduğunu göstermektedir. ${ }^{38}$ Mevcut in vitro çalışmanın en önemli kısıtıılı̆ı ise, ağız içi ortam etkisinin dışlanmış olmasıdır. Bu nedenle, daha doğru sonuçlara ulaşılması adına çalışma örnekleminin doğal dişler olduğu ve in-vivo tasarımda uygulanan çalışmalara intiyaç olduğu görülmektedir.

Çalışmanın diğer kısıtıııklarından biri, örnekleri değerlendirme işleminin simantasyon yapılmadan uygulanmasıdır. Bu durum, restorasyonun simantasyonu sırasında oluşabilecek kenar ve iç yüzey aralığı mesafesinin artışı gibi bir durumu göz ardı etmektedir. Ayrıca, uyum parametrelerinin değerlendirilmesi silikon replikalardan iki yönlü kesit alınarak gerçekleştirilmiş olup, bu durumun tüm yüzey değerlendirmesine izin vermediği için sınırlı bilgi sağladığı düşünülmektedir. Yanı sıra, çalışmada kullanılan konvansiyonel ölçü kayıtları oda sıcaklığında elde edilmiş olup, oda sıcaklığı $\left(18-24^{\circ} \mathrm{C}\right)$ ile ağız kavitesinin sıcaklığı $\left(32^{\circ} \mathrm{C}\right)$ arasındaki farkılığın ölçü netliğini etkilemesi söz konusudur. Bu açıdan, DDT sistemiyle ilgili daha güvenilir sonuçların elde edilmesi adına farklı tedavi protokolleri ve geniş seçeneklerin (implant üstü restorasyonlar gibi) de dahil edildiği çalışmalar gerekmektedir. Çalışmada, örneğin ön ya da arka diş olması sonuçları etkilemekte ve çalışmada tek tip örneklem çeşidinin (büyük azı dişi) kullanılması diğer bir kısıtılık türü olarak rol oynamaktadır.

Tüm bu bahsedilen bilgiler dahilinde gelecek çalışmalarda; çeşitlendirilmiş ölçüm noktalarının kullanılması, kenar ve iç yüzey uyum parametrelerini daha kapsamlı ve üç boyutlu değerlendirmeyi sağlayan inceleme yöntemlerinden faydalanılması, simantasyon öncesi ve sonrası ölçümlerin gerçekleştirilmesi, farklı örnek türleri ve daha geniş örneklem büyüklüğünün tercihi, örnek eldesinde doğal dişlerin kullanılması, farklı restorasyon türleri ve güncel seramik materiallerinin dahil edilmesi ile doğala yakın sonuçlar elde etmek adına ağız içi (in-vivo) şartların ilave olarak incelenmesi önerilmektedir. 
Bu çalışmanın şartları ve kısıtlılıkları dahilinde, aşağıdaki sonuçlara ulaşılmıştır:

1. Direkt dijital yöntemle üretilen kron ve inley restorasyonlar, indirekt dijital ve geleneksel yöntemle üretilen restorasyonlara göre istatistiksel olarak daha iyi kenar ve iç yüzey uyumu sergilemiştir.

2. Tüm çalışma gruplarında elde edilen kenar ve iç yüzey aralık değerleri klinik olarak kabul edilebilir sınırlar içerisinde yer almaktadır.

NOT: Çalışmada herhangi bir yazar, kurum ya da kuruluş ile çıkar çatışması içerisinde bulunmamaktadır. Makale daha önce hiçbir yerde yayınlanmamıs ve yayınlanmak üzere işlem görmemektedir

\section{KAYNAKLAR}

1.Rekow ED. High-technology innovations-and limitations-for restorative dentistry. Dent Clin North Am 1993; 37: 513-24.

2.Piwowarczyk A, Ottl $P$, Büchler A, Lauer $H C$, Hoffmann $A$. In vitro study on the dimensional accuracy of selected materials for monophase elastic impression making. Int J Prosthodont 2002; 15: 168-74.

3. Chandran DT, Jagger DC, Jagger RG, Barbour ME. Two- and three-dimensional accuracy of dental impression materials: Effects of storage time and moisture contamination. Biomed Mater Eng 2010; 20: $243-9$.

4. Thongthammachat S, Moore BK, Barco TM, Hovijitra $\mathrm{S}$, Brown DT, Andres CJ. Dimensional accuracy of dental casts: Influence of tray material, impression material, and time. J Prosthodont 2002; 11: 98108.

5. Wassell RW, Barker D, Walls AW. Crowns and other extra-coronal restorations: impression materials and technique. Br Dent J 2002; 192:679-84,68790.

6.Mehl A, Ender A, Mormann W, Attin T. Accuracy testing of a new intraoral 3D camera. Int J Comput Dent 2009; 12:11-28.

7.Luthardt R, Weber A, Rudolph H, Schöne C, Quaas $S$, Walter $M$. Design and production of dental prosthetic restorations: Basic research on dental CAD/CAM technology. Int J Comput Dent 2002; 5:165-76.
8. Vlaar ST, Van der Zel JM. Accuracy of dental digitizers. Int Dent J 2006; 56: 301-9.

9. Miyazaki T, Hotta Y, Kunii J, Kuriyama S, Tamaki Y. A review of dental CAD/CAM: Current status and future perspectives from 20 years of experience. Dent Mater J 2009; 28: 44-56.

10. Mörmann WH. The evolution of the CEREC system. J Am Dent Assoc 2006; 137:7-13.

11.Tinschert J, Natt G, Spiekermann H, Spiekermann $\mathrm{H}$, Anusavice KJ. Marginal fit of alumina- and zirconia-based fixed partial dentures produced by a CAD/CAM system. Oper Dent 2001; 26: 367-74.

12. Suarez MJ, Gonzalez de Villaumbrosia P, Pradies G, Lozano JF. Comparison of the marginal fit of Procera AllCeram crowns with two finish lines. Int J Prosthodont 2003; 16: 229-32.

13. Bindl A, Mörmann WH. Marginal and internal fit of all ceramic CAD/CAM crown-copings on chamfer preparations. J Oral Rehabil 2005; 32: 441-7.

14. Ender $A$, Mehl $A$. Influence of scanning strategies on the accuracy of digital intraoral scanning systems. Int J Comput Dent 2013; 16: 11-21.

15. Schaefer O, Watts DC, Sigusch BW, Kuepper $H$, Guentsch A. Marginal and internal fit of pressed lithium disilicate partial crowns in vitro: A threedimensional analysis of accuracy and reproducibility. Dent Mater 2012; 28: 320-6.

16. Grasso JE, Nalbandian J, Sanford C, Bailit H. Effect of restoration quality on periodontal health. J Prosthet Dent 1985; 53: 14- 9.

17. Tan PL, Gratton DG, Arnold AMD, Holmes DC. An in vitro comparison of vertical marginal gaps of CAD/CAM titanium and conventional cast restorations. J Prosthet Dent 2008;17:378-83

18. Dedmon HW. The relationship between open margins and marginal designs on full cast crowns made by commercial dental laboratories. J Prosthet Dent 1985; 53: 463-6.

19. Holden JE, Goldstein GR, Hittleman EL, Clark EA. Comparison of the marginal fit of pressable ceramic to metal ceramic restorations. J Prosthet Dent 2009;18: 645-8.

20.Kokubo Y, Ohkubo C, Tsumita Met, Miyashita A, Vult von Steyern P, Fukushima S. Clinical marginal and internal gaps of Procera All Ceram crowns. J Oral Rehabil 2005; 32: 526-30. 
21. Martins LM, Lorenzoni F, Melo AO, Silva LM, Oliveira JL, Oliveira PC, Bonfante G. Internal fit of two all-ceramic systems and metal-ceramic crowns. J Appl Oral Sci 2012; 20:235-40.

22.Contrepois M, Soenen A, Bartala Met, Laviole O. Marginal adaptation of ceramic crowns: A systematic review. J Prosthet Dent 2013; 110:44754.

23.Naumann M, Ernst J, Reich S, Weißhaupt P, Beuer F. Galvano- vs. metal-ceramic crowns: up to 5-year results of a randomized split-mouth study. Clin Oral Invest 2011; 15: 657-60.

24. https://kemaldis.com/magaza/ana-4-zp/

25.Monaco C, Rosentritt M, Llukacej A, Baldissara P, Scotti R. Marginal adaptation, gap width, and fracture strength of teeth restored with different all-ceramic vs metal ceramic crown systems: An in vitro study. Eur J Prosthodont Restor Dent 2016; 24:130-7.

26. Holmes JR, Bayne SC, Holland GA, Sulik WD. Considerations in measurement of marginal fit. ] Prosthet Dent 1989; 62: 405-8.

27.Carlile RS, Owens WH, Greenwood WJ, Guevara $\mathrm{PH}$. A comparison of marginal fit between pressfabricated and CAD/CAM lithium disilicate crowns. Gen Dent 2018; 66:45-8.

28. Yeo IS, Yang JH, Lee JB. In vitro marginal fit of three all-ceramic crown systems. J Prosthet Dent 2003; 90: 459-64.

29. Coli P, Carlsson S. Precision of a CAD/CAM technique for the production of zirconium dioxide copings. Int J Prosthodont 2004; 17:577-80.

30. Wolfart S, Wegner SM, Al-Halabi A, Kern M. Clinical evaluation of marginal fit of a new experimental all-ceramic system before and after cementation. Int J Prosthodont 2003; 16: 587-92.

31. Park SH, Yoo YJ, Shin YJ, Cho BH, Baek SH. Marginal and internal fit of nano-composite CAD/CAM restorations. Restor Dent Endod 2016; 41:37-43.

32.Syrek A, Reich G, Ranftl D, Klein C, Cerny B, Brodesser J. Clinical evaluation of all ceramic crowns fabricated from intraoral digital impressions based on the principle of active wavefront sampling. J Dent 2010; 38: 553-9.

33.Scotti R, Cardelli P, Baldissara P, Monaco C. Clinical fitting of CAD-CAM zirconia single crowns generated from digital intraoral impressions based on active wavefront sampling. J Dent 2011 DOI: 10. 1016/ j. jdent.2011.10.005.
34. Huang Z, Zhang L, Zhu J, Zhao Y, Zhang X. Clinical marginal and internal fit of crowns fabricated using different CAD/CAM technologies. J Prosthodont 2015; 24:291-5.

35. Reich S, Kappe K, Teschner H, Schmitt J. Clinical fit of four-unit zirconia posterior fixed dental prostheses. Eur J Oral Sci 2008; 116:579-84.

36.Abduo J, Lyons K, Swain M. Fit of zirconia fixed partial denture: A systematic review. J Oral Rehabil 2010; 37:866-76.

37. Mert Yüce Ş, Türk AG. Bilgisayar destekli tasarımbilgisayar destekli üretim ve presleme sistemleriyle üretilen porselen laminat venerlerin kenar ve internal uyumlarının karşılaştırılması: İn vitro çalışma. Atatürk Üniv. Diş Hek. Fak. Derg 2017; 27:19-26.

38.Jeong ID, Lee JJ, Jeon JH, Kim JH, Kim HY, Kim WC. Accuracy of complete-arch model using an intraoral video scanner: An in vitro study. J Prosthet Dent 2016; 115:755-9.

39. Aboushelib MN, Elmahy WA, Ghazy MH. Internal adaptation, marginal accuracy and microleakage of a pressable versus a machinable ceramic laminate veneers. J Dent 2012; 40:670-7.

40.Kim JH, Cho BH, Lee JH, Kwon SJ, Yi YA, Shin Y, Roh BD, Seo DG. Influence of preparation design on fit and ceramic thickness of CEREC 3 partial ceramic crowns after cementation. Acta Odontol Scand 2015; 73:107-13.

\section{Yazışma Adresi}

Öğr. Gör. Merve Benli

İstanbul Üniversitesi, Diş Hekimliği Fakültesi, Protetik Diş Tedavisi A.D., İstanbul

Topkapı Mahallesi, Turgut Özal Millet Cd, 34093

Fatih/İstanbul

Tel: +90 212 4142020-30362

Faks: +90 2125310515

E-posta:benlimerve@hotmail.com

merve.benli@istanbul.edu.tr 